\title{
POR UMA ANTROPOLOGIA DOS RESÍDUOS
}

DEBARY, Octave. Antropologia dos restos: da lixeira ao museu. 1. ed. Pelotas-RS: 2017, p.136.

\section{Gleidson de Oliveira Moreira ${ }^{1}$ \\ Cleumar de Oliveira Moreira ${ }^{2}$}

"Meu horizonte cultural é aquele de um empirismo de proximidade, do desvio a curta distância. Enquanto a maior parte dos antropólogos viaja para longe, enfrentando a descentralização geográfica e cultural, eu cultivo um interesse pelo próximo, o próximo na verdade. Aprendo a distanciar-me, mas, permanecendo no lugar" (DEBARY, 2017, p-12).

Fundamentando-se na citação acima, apresentada nas primeiras páginas do livro "Antropologia dos Restos: da lixeira ao museu", do antropólogo, professor na Universidade Paris-Descartes e pesquisador no Centro de Antropologia Cultural do CANHHEL (Sorbonne Paris Cité) e no Laboratório de Antropologia, História e Instituição Cultural da Universidade Federal de Pelotas no Rio Grande do Sul - LAHIC (EHESS-CNRS), Octave Debary; observamos que seus estudos debruçam-se nos interstícios da modernidade enquanto forma de observar lembranças incorporadas aos objetos, mais exatamente em seus traços, sejam eles intencionais ou não. Tal procedimento possibilita perceber como a memória coletiva está depositada nas coisas. Ante o exposto uma reflexão provocativa emerge: de onde começam os objetos e onde terminam os restos (os resíduos, o veneno, o lixo)?

Ao afirmar que distanciar é permanecer no lugar, o autor objetiva estabelecer as bases de uma antropologia da proximidade, balizada no papel das experiências humanas capturadas pelas percepções sensoriais, percepções que são entendidas como sensibilidades individuais ou projeções de significados do indivíduo sobre o mundo a partir de suas relações com o entorno, com as memórias de objetos inexistentes e com a materialidade destes e seus restos.

\footnotetext{
${ }^{1}$ Universidade Federal de Goiás, Brasil. E-mail: kareminus@gmail.com ORCID id: https://orcid.org/0000-0003-3671-2811

${ }^{2}$ Universidade Estadual de Goiás, Faculdade de Anicuns, Brasil.

E-mail: cleumardeoliveira@gmail.com

ORCID id: https://orcid.org/0000-0003-0319-8123
} 
Ao tratar de uma ciência dos resíduos, Debary (2017) recorre à autores por meio de duas matizes: a) os da memória; e b) os da materialidade. No campo da memória ganham ênfase Maurice Halbwachs e Paul Ricouer; e, no campo da materialidade, Alfred Gell e Jorge Latour. Os primeiros são abordados a partir de uma epistemen da memória para análise da materialidade. Halbwachs e Ricouer observam a dimensão biográfica dos objetos, o itinerário de seus atores na formação de um labirinto em uma análise das múltiplas vidas destes. Ao passo que os autores da materialidade aludem nos objetos o seu caráter conceitual de arte e agência, pressupostos teóricos inscritos na tessitura do material passam a compor a essência dos próprios objetos, seja pela estética ou funcionalidade $(\mathrm{p}-23)$.

Em ambas as abordagens, as percepções dos objetos são deslocadas para áreas periféricas da vida cotidiana, o que é observado por Debary (2017) quando se tornam resíduos, constituindo assim peças de mercados de usados e destroços descritos, segundo contextualização de cenários nos quais subsistem. Assim, objetos e os resíduos nos quais se tornam ficam à deriva, suspensos nos museus, garagens e mercados de pulgas até que ações conclusivas os eliminem de vez, incluindo o total apagamento das lembranças.

Mesmo em uma época em que os objetos tornam-se muito diversificados, o autor escolheu a etnologia do próximo como exercício metodológico, uma espécie de no man's land descrito por Philippe Descola ${ }^{3}$, uma contestação observada entre a história contemporânea e a sociologia, entre o estudo das instituições patrimoniais e a literatura popular, entre o folclore e história da arte, como esforço de reunir fragmentos, farrapos consonantes, encontrados, segundo o autor, em uma multidão de anônimos (p-06).

Assim, os objetos atribuem crédito à vida ao validar a utilidade das pessoas transmutadas em coisas, uma ação capitalista potencializada na simultaneamente do uso pela necessidade ou pelo descarte via obsolescência. Ao invés de créditos com nomes sem explicação, o autor mobiliza uma sequência de encontros entre coisas e pessoas cuja relação sobre/e como a ordem do sistema cultural permite compreender o tratamento feito pela sociedade em relação a seu passado, passado presentificado nos resíduos deixados pelos objetos.

O esforço epistemológico empreendido por esse antropólogo coloca, diante das coisas, a condição dos objetos como subprodutos da cultura. Assim, a postura

\footnotetext{
${ }^{3}$ Citação presente no prefácio desta obra.
} 
antropológica de Debary (2017) o projeta ao status de errático, afinal ao empreender a coleta e a observação das tessituras dos traços materiais, isso o coloca em uma relação ambígua na medida em que as comunidades humanas apresentam suas experiências, ligadas ou elaboradas por atores sociais, como testemunho das coisas do passado, sejam experiências de coisas alegres ou não. Isso forma um repositório para a análise da memória e suas ressonâncias em constante movimento de descarte ou persistência pela reutilização (p-38).

Filtrado pela memória, os fragmentos dos objetos analisados por Debary (2017) possibilitam entender como estes se fixam na sociedade contemporânea. O objetivo do autor é buscar no itinerário das múltiplas vidas dos objetos a forma como é operada a sua fixação. É a partir da forma como os objetos foram concebidos e/ou descartados que surge a preocupação com uma ciência dos resíduos, uma noção de resto associada com aquilo que resiste ao desaparecimento, o que constitui um outro lugar de inscrição e testemunho do próprio tempo.

Para tornar mais sistêmico o entendimento de persistência dos objetos e seus resíduos via memória deles subsumidas, Debary (2017)que já postulava em sua trajetória de produção intelectual com publicações: Vide-greniers, muséees, com Annette Becker (eds) (Creaphis-2012); Voyage au Musee du quai Brandy, com Mélanie Roustan, prefaciado por James Clifford (La Documentation francaise, 2012), torna inédita na obra "Antropologia dos restos: da lixeira ao museu uma particularidade", a ideia de como os objetos ultrapassam os seus limites de usos originais, significando a passagem do próprio tempo agregados em um mesmo lugar, e como estes objetos voltam a habitar o presente.

Afinal, se a existência de determinado resíduo é testemunho para o impossível esquecimento dos objetos (coisas); então, o trabalho da memória passa a dedicar-se à domesticação dos sentidos que, naturalmente, garante o redespertar de valores e da consciência da utilidade. Assim, uma nova provocação se objetifica com a perspectiva de que a destruição das coisas é dinâmica natural desejada pela sociedade coisificada. Sacrificar o resto é deletar as memórias individuais que compõem as memórias coletivas; ou seja, eliminar os dejetos é sacrificar parte do patrimônio social orgânica. 
Materializada pela mera ocasião, a obra ${ }^{4}$ compreende um compêndio de artigos que resultaram nas 136 páginas deste livro. A produção é imprescindível para construir um novo marco reflexivo acerca da "Antropologia dos restos". O que foi escrito, se apresenta em estilo refinado e denso. O retorno ao significado, ao habitar dos fragmentos, suscita um possível descarte enquanto resto, resíduo, lixo.

Para efeito de análise categorial do termo resíduo, o livro está dividido em seis capítulos: o primeiro, intitulado, "Da lixeira à fábrica", trata da reutilização de dejetos industriais deixados na pequena "cidade-usina" francesa de Creusot, em ecomuseu (encenação de peças expostas por toda urbe). Nesse capítulo, Debary (2017) toma o tema "resto" como categoria para pensar a organização do espaço doméstico e/ou institucional após o "banimento humano" (força de produção), de Creusot; ou seja, para pensar o humano enquanto resto, também.

O segundo capítulo, "Os mercados da memória" reflete a respeito da circularidade de objetos qualificados de segunda mão que são vendidos em garagens ou mercados de pulgas; neste momento destaca-se o retorno do status social ao objeto; quando, então, este é recolocado ao mercado para a "troca" (relação agência/memória).

O terceiro capítulo, "Do teatro dos objetos", aborda a paixão pelos objetos usados, imprimindo em um objeto ordinário, descartável, fabricado em série, a influência de numerosos registros. Aqui, o museu é colocado como espaço oblíquo, porque deixa os seus visitantes imaginarem, em contato com o cenário atravessado pelas peças, o mundo que fala, e que fala pela vontade do olhar.

O quarto capítulo, "A arte da semelhança", o objeto é colocado em questão por uma arte que recusa estabelecer o colapso do mundo, prefere o redescobrimento, o encaixotamento, a compressão, a recomposição ou o desaparecimento. Este distanciamento cria uma obra para além do objeto, permitindo o estabelecer de uma narrativa que se faz narrar. Nesse capítulo a crítica ancora em uma recusa da idolatria do objeto.

O quinto capítulo, "Do patrimônio ao museu", mostra a ligação do que se quer lançar fora, enviado para a lixeira tudo aquilo que se pretende esquecer, sacrificando e desvencilhando restos, tendo em vista uma possível reciclagem, o que implica na ideia de conservar e guardar o que sobrou.

\footnotetext{
${ }^{4}$ Reúne a produção de intelectuais da Universidade Federal de Pelotas- RS (outubro de 2016) por meio do Programa de Altos Estudos (EAE-CAPES), via projeto Interdisciplinar de Pós-Graduação em Memória Social e Patrimônio Cultural.
} 
No último capítulo, "O objeto como resto", desenvolve-se a partir de uma Antropologia das técnicas, dos artefatos em relação ao não humano. O poder das coisas também está em sua biografia, ali o objeto é colocado como sujeito, tem nome e existencialismo; assim, o resto como resíduo perturba, e sua existência gravita no paradoxo do "ser e não ser", pois o resíduo é cultural e varia de acordo com a situação social, e é condição necessária para a sociedade.

Ao longo do livro, o autor expõe um extenso mosaico de exemplos sobre o papel dos resíduos a partir da captura pelas percepções, um universo de sensibilidades que confere à visão ocidental o papel de metáfora do conhecimento, do esclarecimento à visão de mundo a partir dos objetos e seus lugares.

Em sua análise sobre os materiais e materialidades constitutivas dos objetos, o trabalho ganha estatuto de sentido primordial, sobrecarregado de importância e consciente do distanciamento e diferenciação entre o "eu" e o "nós" (objetos produzidos cujas biografias oferecem traços reveladores de sua época). A demarcação do individual na sociedade ganha simultaneamente a elevação da visão ao posto de sentido próprio de distinção.

Pelo distanciamento, a vista cobra importância dos sentidos de proximidades, um progressivo alijamento do outro através de um novo estatuto do sujeito que modifica e é modificado pelo objeto e os seus restos.

É nessa viagem onírica através das coisas, no meio dos restos do mundo e cujas figuras deambulam uma forma de ser, é na acumulação de riquezas face à aceleração do tempo, que o servilismo utilitário dos objetos em seu valor estético é elogiado, pelo autor. É na perda que se acham objetos inutilizados, são nos fragmentos que a possibilidade de apreendê-lo ou defini-lo que o resto ultrapassa o real, transformando o perturbador em "eterno do transitório".

Recebido 19/12/2018

Aprovado 11/12/2019 